\title{
Validation of the Tswana Versions of the Roland-Morris Disability Questionnaire, Quebec Disability Scale and Waddell Disability Index
}

\begin{abstract}
The use of reliable and valid outcome measures in clinical research as well as clinical practice is very important. Self reported questionnaires are widely used as outcome measures to assess the subjective perception of disability caused by low back pain (LBP). The Roland Morris Disability Questionnaire (RMDQ), Quebec Disability Scale (QDS) and Waddell Disability Index (WDI) have been identified as reliable and valid instruments for assessing disability caused by LPB in English speaking patients. The fact that we do not yet have a validated and published version of the RMDQ, QDS and WDI in a local South African language was the motivation to undertake this study. The three

\begin{tabular}{|} 
De Beer N, MSc'; \\
Stewart A, PhD'; \\
Becker P, PhD \\
Department of Physiotherapy, School of \\
Therapeutic Sciences, Faculty of Health Sciences, \\
University of the Witwatersrand \\
2 Department of Physiotherapy, School of \\
Therapeutic Sciences, Faculty of Health Sciences, \\
University of the Witwatersrand \\
${ }^{3}$ South African Medical Research Council \\
\end{tabular}
questionnaires were translated, back-translated and tested in a final version for use with Tswana speaking subjects. The questionnaires were tested on one hundred respondents, who met the inclusion criteria, at five hospitals in Tswana speaking areas. Of the one hundred respondents 31 were retested 24 hours later. The Visual Analogue Pain Intensity Scale (VAS-Pain) and Disability Rating Index (DRI) were used as correlation tools. There was moderate correlation between the RMDQ and the DRI (0.74) and the WDI and the DRI (0.63). The correlation between the QDS and DRI was strong (0.85). The RMDQ, QDS and WDI correlated moderately with the VAS-Pain (0.63, 0.68 and 0.74, respectively). The RMDQ, QDS and WDI appeared to be internally consistent scales with Cronbach's alpha values of 0.92, 0.95 and 0.75, respectively. The RMDQ, QDS and WDI showed excellent test-retest reliability with intra-class correlation coefficient values of 0.93, 0.91 and 0.84 , respectively. The results suggest that the Tswana versions of the RMDQ, QDS and WDI validated in this study are easy to understand, valid and reliable instruments for the measurement of functional disability caused by LBP in a Tswana speaking population. Therefore these translated instruments may be useful clinical instruments for collecting standardised data on activity limitations resulting from LBP in a Tswana speaking population.
\end{abstract}

KEYWORDS: LOW BACK PAIN, ROLAND MORRIS DISABILITY QUESTIONNAIRE, QUEBEC DISABILITY SCALE, WADDELL DISABILITY INDEX, RELIABILITY, VALIDITY.

\section{INTRODUCTION}

Low back pain (LBP) has proved to be a considerable challenge in both developed and developing countries and is responsible for a major portion of people staying away from work or visiting a medical practitioner (World Health Organisation, 2003). LBP impacts on the functional status of a patient, interfering with basic activities of daily living such as sitting, standing, walking and other work related activities (Kopec, 2000).

According to Beattie \& Maher (1997) one of the most important outcomes of physiotherapy management of LBP is to restore normal function. Measurement tools that evaluate functional limitation in patients with LBP, and examine the change in functional status over time are thus important.

There are numerous objective tests that can be used by the physiotherapist in the clinical setting. These may give an indication of the outcome of the treatment for LBP. However the functional status of many daily activities may not be directly observed by the physiotherapist and will have to form part of the subjective evaluation, assessing them by way of questioning. The only problem with this non standardised way of questioning is that it is unlikely to be very reproducible (reliable) (Streiner \& Norman, 1995).
Standardised self reported outcome measures are a convenient means of collecting and integrating large amounts of information on disability (Davidson $\&$ Keating, 2002). After a review of

\section{Correspondence to:}

$\mathrm{N}$ de Beer

Department of Physiotherapy, School of Therapeutic Sciences, Faculty of Health Sciences, 7 York Road Parktown 2193, University of the Witwatersrand, South Africa.

Email: debeernic@absamail.co.za 
the literature three questionnaires were chosen for this study based on the inclusion criteria used by Davidson \& Keating (2002). The questionnaires must be able to be patient self- administered, brief and easy to complete, have a clear scoring protocol and measure activity limitation and participation restriction.

The Roland Morris Disability Questionnaire (RMDQ) was selected because it is one of the most widely used low back questionnaires with many studies reporting on its reliability and validity. The Quebec Disability Scale was developed by examining certain measurement properties within a larger group of 48 items and this according to Kopec et al. (1996) produced a 20 item questionnaire with superior measurement properties to those questionnaires developed through pure insight. The Waddell Disability Index is a very brief questionnaire (9 items) and asks specific and direct questions and seemed appropriate for use in this study.

In a recent systematic review done by Grotle et al. (2004) all of the above three questionnaires have been recommended for use, on English speaking patients, without the need for further validation studies. However for researchers and clinicians to use these self reported disability questionnaires in other cultures they will need to be translated and culturally adapted. According to Grotle et al. (2003), the translation must be revalidated to achieve an equivalent questionnaire. The benefit of translating questionnaires is that it allows clinicians and researchers to compare the clinical outcomes of many interventions for LBP by large scale meta-analyses (Davidson \& Keating, 2002). The fact that we do not yet have a validated and published version of the RMDQ, QDS and WDI in a local South African language was the motivation to undertake this study.

Reliable and valid Tswana versions of the RMDQ, QDS and WDI, as instruments for the assessment of disability in patients with LBP, have not yet been developed. The purpose of this study then was to translate and culturally adapt the RMDQ, QDS and WDI into Tswana and to establish their validity and reliability for Tswana speaking patients with low back pain.

\section{METHOD}

\section{Research tools}

The questionnaires used for translation and cross cultural adaptation in this study were the RMDQ, QDS and WDI (see Appendix A). Translated and crossculturally adapted Tswana versions of the DRI and VAS-Pain were used to test the construct and concurrent validity of the RMDQ, QDS and WDI.

\section{Translation procedure}

The translation and cross cultural adaptation of the original English versions of the RMDQ, QDS and WDI into Tswana was carried out in accordance with published guidelines (Beaton et al, 2000)

The RMDQ, QDS and WDI were translated into Tswana by two different and independent Tswana speakers. Tswana had to be their home language and they needed to have good English skills.

The translations were compared with one another and with the original English versions. After discussing any discrepancies that may have arisen, consensus was reached and the translated versions were integrated into one common Tswana version for each of the three questionnaires.

Two other Tswana speakers, with good English skills then carried out back-translations of the Tswana versions into English. A bilingual physiotherapist compared the back-translations with each other and with the original English questionnaires and highlighted any gross inconsistencies in the content of the translated versions. The bilingual physiotherapist and one of the original translators then jointly reviewed and fine-tuned the pre-final Tswana versions.

Lastly the pre-final translated questionnaires were tested in a pilot study on ten Tswana speaking subjects. They were briefly interviewed to check what they thought were meant by each question and the chosen response. All the findings were evaluated and the Tswana versions of the RMDQ, QDS and WDI were then finalised.

\section{Research participants}

A total of one hundred Tswana speaking subjects complaining of LBP agreed to take part in the study. The study was conducted over a period of two months. During the first month data were collected from Wilmed Park and Sunningdale private hospitals as well as Duff Scott and Westvaal mining hospitals in Klerksdorp. In the second month the battery of questionnaires was tested at Dr George Mukari government hospital in Tswane. Written permission was granted by all of the hospitals. Ethical clearance was obtained from the University of the Witwatersrand Committee for Research on Human Subjects.

\section{Procedure}

Subjects who consented to participate in the study were asked to complete a questionnaire booklet, which contained an information sheet, consent form, the Tswana versions of the RMDQ, QDS, WDI, DRI and 100mm VAS-Pain. A brief personal data questionnaire was also completed which was kept separately to maintain confidentiality. A Tswana speaking research assistant was present to read (not explain) each question of the Tswana versions of the questionnaires to those subjects who could not read. The researcher was also present during data collection to ensure the coordination of the study logistics.

Construct validity means that an instrument relates to other measures in a way that is to be expected (Trochim, 2001). The use of the DRI as a correlation tool to establish the construct validity of other disability scales has been supported by the literature (Feise \& Menke, 2001, Grotle et al., 2003). To test the construct validity, a significant correlation between the RMDQ, QDS, WDI and the DRI was hypothesized.

Concurrent validity is when a measurement correlates highly with the current performance on some other test (both tests are administered at approximately the same time). If a questionnaire is a valid measure of activity limitation, and if the limitation is due to pain, one would expect a significant correlation of questionnaire scores with self rated pain. Concurrent validity was determined by comparing the scores of the RMDQ, QDS and WDI with the results of the VAS (pain).

Internal consistency indicates the strength of the association between all the items within the test instrument, thus 
assessing the extent to which items within a scale measure a single underlying trait. Cronbach's alpha was used to determine the internal consistency of the questionnaires.

Test-retest reliability is the consistency or repeatability of scores of a measuring instrument when administered on two different occasions. In this study, 31 subjects with LBP were asked to complete the second questionnaire booklet, containing the four disability questionnaires and the VAS pain scale, 24 hours after they completed the first questionnaire booklet.

\section{Statistical analysis}

Internal consistency was measured by means of Cronbach's alpha. Test-retest reliability was determined by using the Intraclass Correlation Coefficient. Construct and concurrent validity were determined by the Pearson Correlation Coefficient.

\section{RESULTS}

\section{Demographic data}

The demographic data of the study population are shown in Table 1.

Of the 100 subjects who participated in the study 95 were female and only 5 were male. The reason for the majority being female subjects in the study was mainly due to the occupations of the subjects (cleaners, kitchen staff, laundry workers and nurses). The majority of subjects had a grade 10 or higher education level.

Translation and cross cultural adaptation A few noteworthy difficulties arose during the development of the questionnaires as there were also certain cultural differences that made the direct translation from the original English versions of the questionnaires into Tswana difficult. For this reason some modifications were performed during the translation process.

\section{QDS}

Question 8: During the pilot study "Walk a few blocks (300-400m)" was found not to be very well understood and was changed to "To walk for a certain distance (300-400m)“.

Table 1: Demographic Data

\begin{tabular}{|l|l|}
\hline Characteristics & Patients $(\mathbf{n = 1 0 0})$ \\
\hline $\begin{array}{l}\text { Age (years) } \\
\text { Rean (SD) }\end{array}$ & $\begin{array}{l}42( \pm 9.13) \\
23-63\end{array}$ \\
\hline Renge & $5 / 95$ \\
\hline $\begin{array}{l}\text { Number of subjects with an educational } \\
\text { level grade 10 or higher }\end{array}$ & 66 \\
\hline $\begin{array}{l}\text { Number of subjects with an educational } \\
\text { level lower than grade 10 }\end{array}$ & 34 \\
\hline
\end{tabular}

SD indicates standard deviation

Table 2: Pearson correlation coefficient of the Tswana versions of RMDQ, QDS and WDI with the DRI and VAS (pain)

\begin{tabular}{|l|l|l|}
\hline & Correlation with the DRI & Correlation with the VAS (pain) \\
\hline RMDQ & 0.74 & 0.63 \\
\hline QDS & 0.85 & 0.68 \\
\hline WDI & 0.63 & 0.74 \\
\hline
\end{tabular}

All correlations are statistically significant $(p<0.001)$

Question 10: "Reach up to high shelves" was not that comprehensible during the pilot study and was changed to "To reach up to the top cupboards".

Question 12: "Run one block (100m)“ was changed to "To run for a certain distance $(100 \mathrm{~m})$ ".

\section{WDI}

Question 1: “30-40 pound suitcase" was dropped as pounds are generally not used in South Africa. The example of a 3-4 year old child was a good enough example of a heavy object and was well understood by the pilot study sample.

Question 3: "Travelling in a bus or car..." As many of the pilot study sample make use of public transport the word car was changed to taxi. Thus it was changed to "Travelling in a bus or taxi...".

Question 9: "Help required with footwear (tights, socks, tying laces etc.)" was translated as "To be unable to put your shoes on or to tie them yourself". It was agreed that this would be better understood.

\section{Validity}

The Pearson correlation coefficient of the Tswana versions of RMDQ, QDS and WDI with the DRI and VAS (pain) is illustrated in Table 2.
Construct validity of the Tswana versions of the RMDQ, QDS and WDI was measured by determining the correlation between them and a Tswana adaptation of the DRI. The QDS showed a strong correlation with the DRI while the WDI and RMDQ had a moderate correlation.

Concurrent validity of the Tswana versions of the RMDQ, QDS and WDI was assessed with their correlation to the VAS pain scale. Moderate correlation was found between the RMDQ, QDS and WDI summed scores and the VAS pain scale.

\section{Internal consistency}

Reliability of the Tswana version of the RMDQ estimated by the internal consistency reached an overall Cronbach's alpha of 0.9240 . Coefficients ranged from 0.9107 (question 14) to 0.9244 (question 15). For all the 20 items, internal consistency for the Tswana translation of the QDS reached a Cronbach's alpha of 0.9538 . Coefficients ranged from 0.9494 (question 15) to 0.9538 (question 20). Internal consistency reliability for the Tswana translation of the WDI reached a Cronbach's alpha coefficient of 0.7505. Coefficients ranged from 0.6966 (question 4) to 0.7473 (question 9). 


\section{Test-retest reliability}

Test-retest reliability was assessed with a third of the sample on two occasions separated by a time interval of 24 hours. ICC values for the RMDQ, QDS and WDI were $0.93,0.91$ and 0.84 , respectively. There was no significant difference between mean RMDQ, QDS and WDI scores on the two test occasions. All three questionnaires showed excellent test-retest reliability as evident by the high ICC values for the two test occasions.

\section{DISCUSSION}

\section{Validity}

As the RMDQ, QDS, WDI and DRI all measure the same construct, namely disability as a result of LBP, one would expect a significant association of the RMDQ, QDS and WDI scores with the DRI score. The Norwegian version of the RMDQ correlated with the DRI (0.68) (Grotle et al., 2003). A study done by Feise \& Menke (2001) to evaluate the psychometric qualities of the Functional Rating Index (another low back disability questionnaire) found the Functional Rating Index correlated with the Disability Rating index (0.76) and the Short Form-12 Physical Component Score (0.76). Another study done by Mousavi et al. (2006) found that the Persian versions of the RMDQ and QDS correlated with the Short Form-12 Physical Component Score (0.62 and 0.69 , respectively). These studies regarded these figures as significant correlations and in this regard the Pearson correlation coefficients of $0.74,0.85$ and 0.63 for the Tswana RMDQ, QDS and WDI, respectively, indicate significant correlation between them and the Tswana DRI.

In the concurrent validity analysis, moderate correlation was found among the RMDQ, QDS and WDI summed scores and the VAS pain scale. The correlation between the Tswana version of the RMDQ and the VAS pain scale was 0.63 which is higher than the Persian (0.36) (Mousavi et al., 2006), Norwegian (0.32) (Grotle et al., 2003) and Spanish (0.35) (Kovacs et al., 2002) versions of the RMDQ, respectively, but lower than the German (0.81) (Wiesinger et al., 1999) and Brazilian (0.79) (Nusbaum et al., 2001) versions. The Tswana version of the QDS also showed moderate correlation with the VAS pain scale $(0.68)$ which is similar to the original English version (0.7) (Kopec et al., 1995) and higher than the French (0.45) (Kopec et al., 1995) and Persian (0.46) (Mousavi et al., 2006) versions of the QDS. The Tswana version of the WDI correlated somewhat better with the VAS pain scale (0.74) than the Tswana RMDQ and QDS. Mousavi et al. (2006) argue that although the association between LBP disability scales and pain rating scales is expected to be good, it should not be very high, otherwise it would suggest that the two instruments are carrying identical information.

\section{Internal consistency}

The Cronbach's alpha for the Tswana version of the RMDQ of 0.92 is good when compared to previously reported values in the Persian (0.83)(Mousavi et al., 2006),German (0.81) (Wiesinger et al., 1999), Spanish (0.84) (Kovacs et al., 2002), Turkish (0.85) (Kucukdeveci et al., 2001), Greek (0.88) (Boscainos et al., 2003), and Japanese (0.86)(Fujiwara et al., 2003), versions of the RMDQ. In this study, the Cronbach's alpha for the Tswana version of the QDS of 0.95 was higher than the Tswana RMDQ and WDI and similar to the alpha coefficient reported by the developers of the scale (0.96) (Kopec et al., 1995) and the Persian version (0.92) (Mousavi et al., 2006) of the QDS. The Cronbach's alpha of the Tswana version of the WDI was 0.75 , which is similar to the coefficient previously reported by Davidson \& Keating (2002).

Bland \& Altman (1997 and Nunnally (1978) agree that for comparing groups, alpha values of 0.7 to 0.8 are considered satisfactory but that for clinical application much higher values of alpha are needed and a minimum of 0.9 is desirable. Thus in this sense the Tswana versions of the RMDQ, QDS and WDI should all be suitable for group analysis. However the Tswana version of the WDI may not be suitable for the interpretation of individual scores in the clinical setting. The small number of items in the WDI probably contributed to the relatively low alpha value compared to the other two scales.

\section{Test-retest reliability}

In this study, 31 patients with low back pain were asked to complete the second questionnaire booklet, containing the four disability questionnaires and the VAS pain scale. The RMDQ, QDS and WDI all showed excellent test-retest reliability with ICC values of $0.93,0.91$ and 0.84

The ICC reported in the present study for the Tswana version of the RMDQ of 0.93 was higher than those reported in previous studies which used the same 24 hour retest interval, Persian (0.86) (31 subjects reteted) (Mousavi et al., 2006), German (0.82) (20 subjects retested) (Wiesinger et al., 1999). The ICC of the Tswana version of the QDS of 0.91 are in accordance with the ICC reported by the developers of the scale $(0.93$ for English speaking respondents, 0.88 for French speaking respondents) (Kopec et al., 1995) and the Persian version (0.86) (Mousavi et al., 2006). The ICC for the Tswana version of the WDI was 0.84 and although no studies have reported on the ICC of the WDI it is above the generally considered acceptable value of 0.7 (Fayers \& Machin, 2000). These results show the high agreement between all the questionnaires' measurements recorded on two occasions over a 24 hour period.

\section{CONCLUSION}

The results suggest that the Tswana versions of the RMDQ, QDS and WDI validated in this study are easy to understand, valid and reliable instruments for the measurement of functional disability caused by LBP in a Tswana speaking population. Therefore these translated instruments may be useful clinical methods for collecting standardised data on activity limitations resulting from LBP in a Tswana speaking population.

\section{ACKNOWLEDGEMENTS}

The authors would like to thank Mrs A Nkusi and Mrs L Jacobs for their contribution to this study. Furthermore, the authors would like to thank the five hospitals for giving permission to conduct the study on their premises. 


\section{REFERENCES}

1. Beaton DE, Bombardier C, Guillemin F, 2000. Guidelines for the process of cross- cultural adaptation of self-report measures. Spine 25: 3186-3191.

2. Beattie P, Maher C, 1997. The role of functional status questionnaires for LBP. Australian Journal of Physiotherapy 43: 29-38.

3. Bland JM, Altman DG, 1997. Statistics Notes: Chronbach's alpha. British Medical Journal 314: 572.

4. Boscainos PJ, Sapcas G, Stilianessi E, Prouskas K, Papadakis SA, 2003. Greek Versions of the Oswestry and Roland Morris Disability Questionnaire. Cinical Orthopaedics and Realated Research 411: 40-53.

5. Davidson M, Keating JL, 2002. A comparison of Five Low Back Disability Questionnaires: Reliability and Responsiveness. Physical Therapy 82: 8-24.

6. Feise RJ, Menke JM, 2001. Functional Rating Index: A new valid and reliable instrument to measure the magnitude of clinical change in spinal conditions. Spine 26: 78-87.

7. Fayers PM. Machin D, 2000. Quality of life: assessment, analysis and interpretation. Wiley: New York.

8. Fujiwara A, Kobayashi N, Saiki K, Kitagawa T, Tamai K, Saotome K, 2003. Association of the Japanese Orthopaedic Association Score with the Oswestry Disability Index, Roland Morris Disability Questionnaire, and Short- Form 36. Spine 28: 1601-1607.

9. Grotle M, Brox Jl, Vollestad NK, 2003. Cross-Cultural Adaptation of the Norwegian Versions of the Roland-Morris Disability
Questionnaire and the Oswestry Disability Index. Journal of Rehabilitation Medicine 35: 241-247.

10. Grotle M, Brox Jl, Vollestad NK, 2004. Functional Status and Disability Questionnaires: What do they assess? A Systematic Review of Back Specific Outcome Questionnaires. Spine 30: $130-140$

11. Grunnesjo M I, Bogefeldt J P, Svardsudd K F, Blomberg S I E, 2004. A randomized controlled clinical trial of stay-active care versus manual therapy in addition to stay-active care: Functional variables and pain. Journal of manipulative and physiological therapeutics 27: 431-441.

12. Kopec JA, 2000. Measuring functional outcomes in patients with back pain. Spine 25: 3110-3114.

13. Kopec JA, Esdaile JM, Abrahamowicz M, Abenheim L, Wood-Dauphinee S, Lamping DL, Williams JI, 1996. The Quebec Back Pain Disabilty Scale: Conceptualization and Development. Journal of Cinical Epidemiology 49: 151161.

14. Kopec JA, Esdaile JM, Abrahamowicz M, Abenheim L, Wood-Dauphinee S, Lamping DL, Williams JI, 1995. The Quebec Back Pain Disabilty Scale: Measurement Properties. Spine 20: 341-352.

15. Kovacs RM, Llobera J, Gil del Real MT, Abraira V, Gestoso M, Fernandez C, 2002. Validation of the Spanish Version of the Roland Morris Questionnaire. Spine 27: 538-542.

16. Kucukdeveci AA, Tennant A, Bhan $A H$, Niyazoglu H, 2001.Validation of the Turkish Version of the Roland Morris Disability Questionnaire for use in low back pain. Spine 26: 2738-2743.
17. Mousavi SJ, Parnianpour M, Mehdian $\mathrm{H}$, Montazeri A, Mobini B, 2006. The Oswestry Disability Index, the Roland Morris Disability Questionnaire, and the Quebec Back Pain Disability Scale: Translation and Validation Studies of the Iranian Versions. Spine 31: 454459.

18. Nusbaum L, Natour J, Ferraz MB, Goldenberg J, 2001. Translation, adaptation and validation of the Roland-Morris questionnaire-Brazil Roland-Morris. Brazilian Journal of Medical and Biological Research 34: 203-210.

19. Nunnally JC, 1978. Psychometric Theory. New York: McGraw Hill.

20. Roland M, Morris R, 1983. A study of the natural history of back pain part 1: development of a reliable and sensitive measure of disability in low back pain. Spine 8: 141-144.

21. Streiner DL, Norman GR, 1995. Health Measurement Scales: A Practical Guide to their Development and Use. Oxford: Oxford University Press.

22. Trochim WMK, 2001.The Research Methods Knowledge Base. Atomic Dog Publishing: Cincinnati.

23. Waddell G, Main GJ, 1984. Assessment of severity in low-back disorders. Spine 9: 204208.

24. Wiesinger GF, Nuhr $M$, Quittan $M$, Eoenbichler G, WIfl G, Falka-Moser V, 1999. Oross-cultural adaptation of the Roland-Morris Questionnaire for German-speaking patients with low back pain. Spine 24: 1099-1103.

25. World Health Organization, 2003. WHO Technical Report Series. The burden of musculoskeletal conditions at the start of the new millennium. Geneva: World Health Organization.

\section{Appendix A: Original English versions of the RMDQ, QDS and WDI}

\section{Waddell Disability Index (Waddell \& Main, 1984)}

When your back hurts, you may find it difficult to do some of the things you normally do.

Mark $(\boldsymbol{V}$ ) only the sentences that describe you today...

1. Help required or avoid heavy lifting (30-40 pound suitcase child 3-4 years old) ( )

2. Sitting generally limited to less than one half hour ( )

3. Travelling in a car or bus generally limited to less than one half hour $($ )

4. Standing in 1 place generally limited to less than one half hour. ( )

5. Walking generally limited to less than one half hour. ( )

6. Sleep disturbed regularly by low back pain (i.e. 2 times per week) ( )

7. Regularly miss or curtail social activities (excluding sports) ( )
8. Diminished frequency of sexual activity ( )

9. Help regularly required with footwear (tights socks tying laces etc.) ( )

\section{Roland-Morris Disability Questionnaire (Roland \& Morris, 1983)}

When your back hurts, you may find if difficult to do some of the things you normally do.

Mark $(\boldsymbol{V})$ only the sentences that describe you today....

1. I stay at home most of the time because of my back. ( )

2. I change position frequently to try to get my back comfortable. ( )

3. I walk more slowly than usual because of my back. ( )

4. Because of my back, I am not doing any jobs that I usually do around the house. ( )

5. Because of my back, I use a handrail to get upstairs. ( )

6. Because of my back, I lie down to rest more often. ( ) 
7. Because of my back, I have to hold on to something to get out of an easy chair. ( )

8. Because of my back, I try to get other people to do things for me. ( )

9. I get dressed more slowly than usual because of my back. ( )

10. I only stand up for short periods of time because of my back. ( )

11. Because of my back, I try not to bend or kneel down. ( )

12. I find it difficult to get out of a chair because of my back. ( )

13. My back is painful almost all of the time. ( )

14. I find it difficult to turn over in bed because of my back. ( )

15. My appetite is not very good because of my back. ( )

16. I have trouble putting on my sock (or stockings) because of the pain in my back. ( )

17. I can only walk short distances because of my back pain. ( )

18. I sleep less well because of my back. ( )
19. Because of my back pain, I get dressed with the help of someone else. ( )

20. I sit down for most of the day because of my back. ( )

21 I avoid heavy jobs around the house because of my back. ( )

22. Because of back pain, I am more irritable and bad tempered with people than usual. ( )

23. Because of my back, I go upstairs more slowly than usual. ( )

24. I stay in bed most of the time because of my back. ( )

The Quebec Disability Scale (Kopec et al. 1995)

This questionnaire is about the way your back pain is affecting your daily life. People with back problems may find it difficult to perform some of their daily activities. We would like to know if you find it difficult to perform any of the activities listed below, because of your back. For each activity there is a scale of 0 to 5 . Please choose one response option for each activity (do not skip any activities) and circle the corresponding number.

Today, do you find it difficult to perform the following activities because of your back?

\begin{tabular}{|c|c|c|c|c|c|c|}
\hline & $\begin{array}{l}0 . \\
\text { Not } \\
\text { difficult } \\
\text { at all }\end{array}$ & $\begin{array}{l}1 . \\
\text { Minimally } \\
\text { difficult }\end{array}$ & $\begin{array}{l}2 . \\
\text { Somewhat } \\
\text { difficult }\end{array}$ & $\begin{array}{l}3 . \\
\text { Fairly } \\
\text { difficult }\end{array}$ & $\begin{array}{l}4 . \\
\text { Very } \\
\text { difficult }\end{array}$ & $\begin{array}{l}5 . \\
\text { Unable to } \\
\text { do }\end{array}$ \\
\hline \multicolumn{7}{|l|}{ 1. Get out of bed } \\
\hline \multicolumn{7}{|l|}{ 2. Sleep through the night } \\
\hline \multicolumn{7}{|l|}{ 3. Turn over in bed } \\
\hline \multicolumn{7}{|l|}{ 4. Ride in a car } \\
\hline \multicolumn{7}{|l|}{ 5. Stand up for $20-30$ minutes } \\
\hline \multicolumn{7}{|l|}{ 6. Sit in a chair for several hours } \\
\hline \multicolumn{7}{|l|}{ 7. Climb one flight of stairs } \\
\hline \multicolumn{7}{|l|}{ 8. Walk a few blocks (300-400 m) } \\
\hline \multicolumn{7}{|l|}{ 9. Walk several kilometres } \\
\hline \multicolumn{7}{|l|}{ 10. Reach up to high shelves } \\
\hline \multicolumn{7}{|l|}{ 11. Throw a ball } \\
\hline \multicolumn{7}{|l|}{ 12. Run one block (about 100m) } \\
\hline \multicolumn{7}{|l|}{ 13. Take food out of the refrigerator } \\
\hline \multicolumn{7}{|l|}{ 14. Make your bed } \\
\hline \multicolumn{7}{|l|}{ 15. Put on socks (pantyhose) } \\
\hline \multicolumn{7}{|l|}{ 16. Bend over to clean the bathtub } \\
\hline \multicolumn{7}{|l|}{ 17. Move a chair } \\
\hline \multicolumn{7}{|l|}{ 18. Pull or push heavy doors } \\
\hline \multicolumn{7}{|l|}{ 19. Carry two bags of groceries } \\
\hline 20. Lift and carry a heavy suitcase & & & & & & \\
\hline
\end{tabular}




\section{Appendix B: Tswana versions of the RMDQ, QDS and WDI}

\section{Lenaane-tatelano la Bogole la Waddell}

Fa mokwatla wa gago o le botlhoko, o ka fitlhela go le thata mo go wena go dira dilo dingwe tse o tlwaetseng go di dira.

Tshwaya fela dipolelo tse di go thalosang mo malatsing a no ....

1. Thuso e a thokega kgotsa o tila go tsholetsa dilo tse di boima (kheisi ya diaparo ya diponto di le 30-40; ngwana wa dingwaga di le 3-4). ( )

2. Go nna ka kakaretso go lekanyeditswe go nako e e fa tlase ga seripa sa ura. ( )

3. Leeto la sejanaga kgotsa bese le lekanyeditswe go nako e e fa tlase ga seripa sa ura. ( )

4. Go ema mo lefelong le le lengwe go lekanyeditswe go nako e e fa tlase ga seripa sa ura. ( )

5. Go tsamaya ka dinao go lekanyeditswe go nako e e fa tlase ga seripa sa ura. ( )

6. Boroko ka metlha bo tlhobaediwa ke setlhabi sa bokwatlase jwa mokwatla (ke gore, makgetlo a le 2 ka beke). ( )

7. O fetiwa kgotsa o kgaotsa ditiro tsa botsalano (go sa akaretse metshameko). ( )

8. Ngotla makgetlo a go tsena mo thobalanong. ( )

9. Thuso e thokega ka metlha mo go rwaleng mo maotong (dikausu tse di pitlaganyang, go bofa megala ya ditlhako, le tse dingwe.) ( )

\section{Bukana-potso ya Roland-Morris ya Ditlhabi mo Bokwatlaseng jwa Mokwatla le Bogole}

Fa mokwatla wa gago o le botlhoko, o ka fitlhela go le thata mo go wena go dira dilo dingwe tse o tlwaetseng go di dira.

Tshwaya fela dipolelo tse di go thalosang mo malatsing a no....

1. Ke nna fa gae nako e ntsi ka ntlha ya mokwatla wa me. ( )

2. Ke fetola mokgwa wa go nna kgafetsa-kgafetsa go leka go dira gore mokwatla wa me o phuthologe. ( )

3. Ke tsamaela ka bonya go feta tlwaelo ka ntlha ya mokwatla wa me. ( )

4. Ke retelelwa ke ditiro tsa selapa tse ken eng ke di kgona pele, ka ntlha ya mokwatla. ( )

5. Ka ntlha ya mokwatla wa me, ke dirisa seikokotlelo sa seatla go ya kwa bopalamelong jo bo kwa godimo. ( )

6. Ka ntlha ya mokwatla wa me, ke sekama gangwe le gape go ikhutsa. ( )

7. Ka ntlha ya mokwatla wa me, ke tshwanetse go itshwarelela ka sengwe go tloga mo setulong sa me se se bonolo. ( )

8. Ka ntlha ya mokwatla wa me, ke leka go batla batho ba bangwe go ntirela dilo.
9. Ke aparela ka bonya go feta ka metlha ka ntlha ya mokwatla wa me. ( )

10. Ke emelela fela nako e khutshwane ka ntlha ya mokwatla wa me. ( )

11. Ka ntlha ya mokwatla wa me, ke leka gore ke se ka ka inama kgotsa go khubama. ( )

12. Go thata mo go nna go tloga mo setulong ka ntlha ya mokwatla wa me. ( )

13. Mokwatla wa me o na le ditlhabi e ka nna ka dinako tsotlhe. ( )

14. Go thata mo mo go nna go iphetola mo bolaong ka ntlha ya mokwatla wa me.

15. Ga ke na keletso e e siameng ya dijo ka ntlha ya mokwatla wa me. ( )

16. Ke thatafalelwa ke go rwala kausu kgotsa kausu ya basadi ka ntlha ya setlhabi se se mo mokwatlang wa me. ( )

17. Ke kgona fela go tsamaya sekgala se se khutshwane ka ntlha ya setlhabi mo mokwatlang wa me. ( )

18. Ga ke robale monate, ka ntlha ya mokwatla. ( )

19. Ka ntlha ya setlhabi mo mokwatlang wa me, ke apara ka thuso ya motho yo mongwe. ( )

20. Ke nna fa fatshe nako e ntsi ya letsatsi ka ntlha ya mokwatla wa me. ( )

21. Ke tila ditiro tse di boima tsa fa gae ka ntlha ya mokwatla wa me. ( )

22. Ka ntlha ya setlhabi mo mokwatlang wa me, ke betwa ke pelo e bile ke felela batho pelo go gaisa ka metlha. ( )

23. Ka ntlha ya mokwatla wa me, ke ya kwa bonamelelong jo bo kwa godimo ka iketlo go feta ka metlha. ( )

24. Ke thola ke robetse bontsi jwa nako, ka nthla ya mokwatla. ( )

Selekanyetso (sekale) sa Quebec sa kgolofalo ka ntlha ya ditlhabi mo mokwatleng:

Bukanapotso e, e ka ga ka moo setlhabi sa mokwatla wa gago se nang le seabe mo bophelong jwa gago jwa letsatsi le letsatsi ka teng. Batho ba ba nang le mathata a mekwatla ba fitlhela go le boima go diragatsa ditiro dingwe tsa bona tsa letsatsi le letsatsi. Re rata go itse fa e le gore o ketefalelwa ke go diragatsa ditiro dingwe tse di kwadilweng fa tlase fa ka ntlha ya mokwatla wa gago. Tiro nngwe le nngwe e emetswe ke sekale sa 0 go ya go 5. Tswee-tswee thopha karabo e le nngwe boemong jwa tiro nngwe le nngwe (se tlole tiro e pe) mme o thale tshekeletsa go dikologa palo e e tsamaelanang le karabo ya gago. 
Today, do you find it difficult to perform the following activities because of your back?

\begin{tabular}{|c|c|c|c|c|c|c|}
\hline & $\begin{array}{l}0 . \\
\text { Ga go } \\
\text { thata le } \\
\text { e seng }\end{array}$ & $\begin{array}{l}1 . \\
\text { Go thata } \\
\text { go le go } \\
\text { nnye }\end{array}$ & $\begin{array}{l}2 . \\
\text { Go thata } \\
\text { go se } \\
\text { kae }\end{array}$ & $\begin{array}{l}3 . \\
\text { Go thata } \\
\text { go utlwala }\end{array}$ & $\begin{array}{l}4 . \\
\text { Go thata } \\
\text { mo go } \\
\text { maswe }\end{array}$ & \begin{tabular}{|l}
5. \\
Ga a \\
kgone go \\
dira
\end{tabular} \\
\hline \multicolumn{7}{|l|}{ 1. Go tswa mo bolaong } \\
\hline \multicolumn{7}{|l|}{ 2. Go robala bosigo botlhe } \\
\hline \multicolumn{7}{|l|}{ 3. Go iphetola mo dikobong } \\
\hline \multicolumn{7}{|l|}{ 4. Fa ke palame koloi } \\
\hline \multicolumn{7}{|l|}{$\begin{array}{l}\text { 5. Go ema ka dinao metsotso e le } \\
20-30\end{array}$} \\
\hline \multicolumn{7}{|l|}{$\begin{array}{l}\text { 6. Go nna mo setulong diura di le } \\
\text { mmalwa }\end{array}$} \\
\hline \multicolumn{7}{|l|}{ 7. Go thatloga ditepese } \\
\hline \multicolumn{7}{|l|}{$\begin{array}{l}\text { 8. Go tsamaya sekgalanyana } \\
\text { (sa } 300-400 \mathrm{~m})\end{array}$} \\
\hline \multicolumn{7}{|l|}{ 9. Go tsamaya dikilometara di se kae } \\
\hline \multicolumn{7}{|l|}{$\begin{array}{l}\text { 10. Go fitlhelela dillaiki tse di kwa } \\
\text { godimo }\end{array}$} \\
\hline \multicolumn{7}{|l|}{ 11. Go latlhela kgwele } \\
\hline \multicolumn{7}{|l|}{$\begin{array}{l}\text { 12. Go taboga sekgalanyana } \\
\text { (sa } 100 \mathrm{~m})\end{array}$} \\
\hline \multicolumn{7}{|l|}{ 13. Go ntsha dijo mo setsidifatsing } \\
\hline \multicolumn{7}{|l|}{ 14. Go alola bolao jwa gago } \\
\hline \multicolumn{7}{|l|}{$\begin{array}{l}\text { 15. Go rwala dikausu (dikausu tsa } \\
\text { basadi) }\end{array}$} \\
\hline \multicolumn{7}{|l|}{ 16. Go inama ke phepafatsa bata } \\
\hline \multicolumn{7}{|l|}{ 17. Go sutisa setilo } \\
\hline \multicolumn{7}{|l|}{$\begin{array}{l}\text { 18. Go goga kgotsa go kgarametsa } \\
\text { mabati a a boima }\end{array}$} \\
\hline \multicolumn{7}{|l|}{$\begin{array}{l}\text { 19. Go rwala dikgetse di le pedi tsa } \\
\text { dijo tse di tswang go rekwa }\end{array}$} \\
\hline $\begin{array}{l}\text { 20. Go kuka le go rwala sutukheisi } \\
\text { e kima? }\end{array}$ & & & & & & \\
\hline
\end{tabular}

